\title{
Fetal RBCs Potential in Obstetric Protocols to Minimize Fetomaternal Hemorrhage
}

\author{
Hasnaa A. Abo-Elwafa, Salah A. Ismail, Ibrahim M. A. Hassanin, Rania M. Ahmed \\ Sohag Faculty of Medicine, Sohag University, Sohag, Egypt \\ Email: hasnaa_aboalwafa@med.sohag.edu.eg
}

How to cite this paper: Abo-Elwafa, H.A., Ismail, S.A., Hassanin, I.M.A. and Ahmed, R.M. (2017) Fetal RBCs Potential in Obstetric Protocols to Minimize Fetomaternal Hemorrhage. Open Journal of Blood Diseases, 7, 51-63.

https://doi.org/10.4236/ojbd.2017.71006

Received: January 16, 2017

Accepted: March 28, 2017

Published: March 31, 2017

Copyright $\odot 2017$ by authors and Scientific Research Publishing Inc. This work is licensed under the Creative Commons Attribution-NonCommercial International License (CC BY-NC 4.0). http://creativecommons.org/licenses/by-nc/4.0/

\begin{abstract}
Background: During pregnancy a small number of fetal RBCs (Red Blood Cells) enter maternal blood without risk, and incidence of significant fetomaternal hemorrhage (FMH) and isoimmunization depends on how much fetal blood enters maternal circulation; the use of flow cytometer (FCM) in FMH detection is considered the best laboratory technique. Aims: To evaluate role of FCM in FMH estimation to optimize delivery protocols and decrease isoimmunization. Subject and Method: 100 pregnant women at labor were included, equally classified into early cord clamping (ECC) and delayed cord clamping (DCC) groups, each including 25 women delivered vaginally and 25 with caesarian section; the control groups included 20 non-pregnant females, 20 at $3^{\text {rd }}$ trimester and 20 neonates. Fetal RBCs were done on Becton Dickinson (B.D) FCM, and the reagents used were 5-Glutaraldehyde 0.5\% Sigma cat. G5882, flouroscine isothiocyanite (FITC) anti-hemoglobin F (Hb-F) cat. 555748, anti-carbonic anhydrase, Triton-X100 solution and Alsever's solution cat. HFH-11, 0.1\% phosphate buffer saline/bovine serum albumin (PBS/BSA). Statistical Analysis: Mann Whitney's U-test, Chi-squared, Fischer's Exact tests, and SPSS for windows version 15.0. Results: There was a significant increase in the volume of the FMH in the ECC compared to DCC groups ( $\mathrm{p}<$ 0.0001 ), also in the vaginal delivery comparing to caesarian section subgroups within the DCC group ( $<<0.01$ ), and in the ECC compared to DCC within caesarian section subgroup $(p<0.02)$. Conclusion: Fetal RBCs estimation by FCM is good; perinatal laboratory test should be done in routine investigations, as a guide for obstetric techniques that can alter FMH volume and decrease subsequent isoimmunization.
\end{abstract}

\section{Keywords}

Fetomaternal Hemorrhage, Obstetric Protocols, Flow-Cytometer

\section{Introduction}

The entry of fetal RBCs into the maternal blood occurs so commonly during 
pregnancy which is clinically insignificant with volume $<0.5 \mathrm{~mL}$ [1]. Maternal and fetal RBCs differ in their hemoglobin F content, while fetal RBCs mainly contain hemoglobin F, and the maternal RBCs contain a small percent of hemoglobin F $2 \%$ in the background of adult hemoglobin [2]. It has been suggested that volume of fetal RBCs in maternal blood increases as pregnancy progresses, particularly in the third trimester. Different fetal cell types can be detected in the maternal circulation, such as fetal RBCs, fetal leukocytes, stem cells of fetal origin and free fetal DNA [3] [4]. The most adverse effect of FMH is maternal isoimmunization, which occurred as a result of $0.5 \mathrm{ml}$ of fetal blood introduced into maternal circulation [5]. FMH may also trigger platelet isoimmunization, which can potentiate other autoimmune diseases and also lead to preeclampsia [6].

FCM is a new and precise method to quantify fetal red cells in the maternal blood [2]. The first FCM methods for detection of FMH were based on anti-D antibodies [7] [8]. The methods that used monoclonal antibodies to ( $\mathrm{Hb} \mathrm{F}$ ) were developed later [9], in which the percent of RBCs containing $\mathrm{Hb} F$ in the maternal blood was used to calculate the volume of Rh positive cells [10]. One of the unique features of FCM is that it can measure fluorescence per one cell [11] [12]. Other method for FMH detection is the Kleihauer-Betke (K-B) acid-elution, which has been considered the cornerstone for detection of FMH for many years ago. The clinical usefulness of the K-B assay is out of discussion, but it was subjected to high interlaboratory difference and individual variations, because it depends on observer discrimination between fetal and adult RBCs [13] [14] [15]. Therefore, Hb F based FCM methods decrease false positive results in patients with increased F-cells due to other hematologic diseases [16] [17].

The World Health Organization states the optimum time for cord clamping occurring when the circulation in the cord has been ceased, and the cord is flat and pulseless [18] [19]. In cord clamping time protocols, DCC is defined as the cord which has been clamped after the onset of respiration, one minute by vaginal delivery and 40 seconds by caesarian section so the vascular bed expansion may facilitate placental transfusion to the baby and decrease the FMH [20]. But ECC is defined as the umbilical cord which is usually clamped shortly in the first 20 seconds after birth [21]. So ECC time protocol disrupts physiology of birth, as it prevents baby from still-functioning placenta, so most of blood returns back to the maternal circulation, ignoring benefits of extra blood volume to the baby [22] [23]. The benefit of DCC time protocol is that it allows enough time for fetal blood in the placenta drawn to the infant at birth, so placental transfusion provides the infant with additional 30\% more blood volume [24].

\section{Subjects and Methods}

The study was conducted in Clinical Pathology Department and Emergency Unit of Obstetrics and Gynecology Department at Sohag University Hospital from February 2014 to January 2015. 


\subsection{Ethical Consideration}

The Medical Ethical Review Board of Sohag University Faculty of Medicine approved the protocol for collecting maternal blood samples for research purposes. All recruited women had given a written informed consent. The medical records of all women were reviewed. All procedures performed in studies involving human participants were in accordance with the ethical standards of the institutional and/or national research committee and with the 1964 Helsinki declaration.

\subsection{Study Design}

Our study included one hundred pregnant women at labor, 20 non pregnant control females, 20 pregnant females in the late pregnancy and 20 neonates classify as follow:

Group I: fifty pregnant women had ECC time protocol, divided into:

Subgroup A: twenty five pregnant women were delivered vaginally.

Subgroup B: twenty five pregnant women were delivered by caesarian section.

Group II: fifty pregnant women had DCC time protocol, divided into:

Subgroup C: twenty five pregnant women were delivered vaginally.

Subgroup D: twenty five pregnant women were delivered by caesarian section.

Group III: control groups: includes:

Subgroup E: negative control for FMH 20 non pregnant females.

Subgroup F: 20 women at $3^{\text {rd }}$ trimester for physiologic FMH values during pregnancy.

Subgroup G: positive auto-control 20 neonates from delivery outcome for fetal $\mathrm{Hb}$.

\subsection{Inclusion Criteria}

Single live fetus, full term pregnancy, spontaneous onset of labor, by cesarean section or vaginal delivery route.

\subsection{Exclusion Criteria}

Multiple fetuses, dead fetus, preterm pregnancy, antepartum hemorrhage, hemoglobinpathies (sickle cell anemia and thalassemia), preeclampsia and diabetes mellitus.

All cases included in this study were subjected to the following:

Complete medical and obstetric history.

Complete physical and obstetrical examination.

Ultrasonography to assess the gestational age and the fetal biophysical profile.

\subsection{The Obstetric Techniques}

Including the route of delivery vaginal or cesarean delivery and the cord clamping time protocol:

DCC: the umbilical cord clamped after one minute in vaginal delivery and forty seconds in caesarian section. 
ECC: the umbilical cord clamped within 20 second of delivery of the fetus whiles the fetus at or below the level of the placenta.

\subsection{Laboratory Investigations}

Sampling: $3 \mathrm{ml}$ of venous blood were withdrawn from the mothers into $\mathrm{K}$ EDTA tubes (B.D) after first 12 hours of delivery used for complete blood picture, blood group, and FCM assay for fetal RBCs. As regard neonates one $\mathrm{ml}$ of blood from foot puncture or minute superficial vein delivered on pediatric K-EDTA tubes in the $1^{\text {st }} 24$ hours after birth for complete blood picture, blood grouping and FCM assay.

FCM assay of fetal RBCs: B.D, FCM four colors FACS caliber (USA) equipped with Cell Quest software used for the estimation of fetal red blood cells in maternal blood.

\section{The following materials were used:}

Falcon tubes (B.D Biosciences) Ref. 352,052, fetal cell count kit by IQ products containing: FITC (mouse IgG1, k-isotype control cat. No. 555748) directed towards $\mathrm{Hb} \mathrm{F}$, and anti-carbonic anhydrase antibody directed towards maternal RBCs, Triton-X-100, 0.1 working solution is prepared in 0.1\% PBS/BSA, Alsever's solution cat. HFH-11, glutaraldehyde $0.05 \%$ : provided by sigma cat. No G5882, formaldehyde obtained from polyscienece cat. No. 04018 PH7.4.

Procedure: The EDTA blood samples were fixated in $0.5 \%$ glutaraldehyde solution ( 3 volume +1 volume) for ten minutes at room temperature. The fixated cells were washed in $2 \mathrm{ml}$ PBS/BSA (0.1\%) and centrifuged at $600 \mathrm{~g}$ for five minutes. This was done three times and some RBCs were lysed. The supernatant was removed and the cell pellet was permeablized by adding Triton-X-100, it is a non-ionic class A detergent. It is a fast-acting permeabilzing agent; however, it may induce dramatic modifications in the FSC/SSC parameters, and then incubating for three to five minutes at room temperature [25].

Triton-X-100 treated cells were washed by centrifuging for five minutes at 600 $\mathrm{g}$ with $2 \mathrm{ml} \mathrm{PBS} / \mathrm{BSA}$ at room temperature $\left(18^{\circ} \mathrm{C}-20^{\circ} \mathrm{C}\right)$. This process enabled monoclonal antibodies to penetrate the cellular membranes. Then the supernatant was removed and the re-suspended cell pellet was mixed in $0.5 \mathrm{ml}$ of PBS/BSA, before FTIC-conjugated monoclonal antibodies and anti-carbonic anhydrase antibodies were added and incubated for fifteen minutes at room temperature and in the dark. After that the antibody stained cells were washed in $2 \mathrm{ml} \mathrm{PBS} / \mathrm{BSA}$ and centrifuged at $600 \mathrm{~g}$ for five minutes. The supernatant was removed and the re-suspended cell pellet was mixed with $0.5 \mathrm{ml}$ of $1 \%$ formaldehyde in PBS/BSA and stored in the dark prior to analysis.

\section{Determination of total fetal RBCs volume:}

The total number of fetal RBCs was counted by FCM.

The total number of maternal RBCs was approximated to 50,000 (normal reference rate for adult females 42,000 to 55,000). The percentage of fetal RBCs in total RBCs was calculated. The total volume of fetal RBCs in maternal circulation was determined through the percentage of fetal RBCs in the total RBCs, as- 
suming a total maternal circulatory volume.

\section{Statistical Analysis}

Demographic data, primary and secondary outcomes of the main two groups were compared using the t-test, Mann-Whitney's U-test (for non-parametric variables), Chi-squared and Fischer's Exact tests (for categorical measures), and SPSS $^{\circledast}$ for windows ${ }^{\circledast}$ version 15.0 were used.

\section{Results}

One hundred women at delivery were assessed for eligibility, 20 non pregnant negative control, 20 pregnant females in third trimester as pregnancy base line value of $\mathrm{Hb} \mathrm{F}$ control and 20 neonates as positive control. We therefore had 50 women who underwent ECC time protocol and 50 women who underwent DCC time protocol for the final analysis. In each group, 25 women were delivered vaginally and 25 women were delivered by caesarian section.

Table 1 represents the demographic data of the studied females, there is insignificant difference in the mean age, parity and gestational age in ECC time protocol group compared to DCC time protocol group $(28.14 \pm 6.40$ and $29.98 \pm$ 6.56 , respectively; $\mathrm{p}>0.16)$.

Table 1. Clinical characterization of the studied population.

\begin{tabular}{|c|c|c|c|c|c|c|c|}
\hline \multirow{2}{*}{ Groups Subgroup (No.) Item } & \multicolumn{2}{|c|}{$\begin{array}{c}\text { Group I } \\
\text { ECC }(n=50)\end{array}$} & \multicolumn{2}{|c|}{$\begin{array}{c}\text { Group II } \\
\text { DCC }(n=50)\end{array}$} & \multicolumn{3}{|c|}{$\begin{array}{l}\text { Group III } \\
\text { Controls }\end{array}$} \\
\hline & $\mathrm{A}(\mathrm{n}=25)$ & $B(n=25)$ & $C(\mathrm{n}=25)$ & $\mathrm{D}(\mathrm{n}=25)$ & $E(n=20)$ & $\mathrm{F}(\mathrm{n}=20)$ & $\mathrm{G}(\mathrm{n}=20)$ \\
\hline Age (year) Mean \pm SD & $28 \pm 7.30$ & $28.28 \pm 5.51$ & $30.56 \pm 6.06$ & $29.4 \pm 7.11$ & $31.3 \pm 5.6$ & $27.4 \pm 4.62$ & \multirow{2}{*}{24 hours } \\
\hline Median (Range) & $29(16-41)$ & $29(20-40)$ & $30(17-42)$ & $28(17-41)$ & $28(22-39)$ & $21(19-38)$ & \\
\hline p-values & \multicolumn{7}{|c|}{$\begin{array}{l}\text { ECC vs. DCC; E vs. ECC \& DCC; F vs. ECC; DCC \& E; A vs. B; C vs. D } \\
\text { All ( } p>0.05) \text { NS }\end{array}$} \\
\hline Parity Mean \pm SD & $3.36 \pm 2.36$ & $3.36 \pm 1.25$ & $3.08 \pm 1.78$ & $4.32 \pm 2.98$ & $2.52 \pm 1.6$ & $4.24 \pm 1.67$ & ----- \\
\hline Median (Range) & $3(0-9)$ & $3(0-9)$ & $3(0-7)$ & $4(0-10)$ & $3(0-6)$ & $4(0-7)$ & ---- \\
\hline p-values & \multicolumn{7}{|c|}{$\begin{array}{l}\text { ECC vs. DCC; E vs. ECC \& DCC; F vs. ECC; DCC \& E, A vs. B; C vs. D } \\
\text { All ( } p>0.05) \text { NS }\end{array}$} \\
\hline Gestational age (Ws.) Mean \pm SD & $38.72 \pm 1.14$ & $38.4 \pm 1.08$ & $38.52 \pm 1.16$ & $38.28 \pm 0.14$ & $32.7 \pm 1.5$ & ----- & ----- \\
\hline Median (Range) & $39(37-40)$ & $39(37-40)$ & $39(37-40)$ & $38(37-40)$ & $32(30-34)$ & ---- & ----- \\
\hline p-values & \multicolumn{7}{|c|}{$\begin{array}{l}\text { ECC vs. DCC; E vs. ECC \& DCC; F vs. ECC, DCC \& E; A vs. B; C vs. D } \\
\text { All }(p>0.05) \text { NS }\end{array}$} \\
\hline FCM Gated fetal RBCs \% & $9.65 \pm 1.96$ & $7.94 \pm 2.52$ & $6.41 \pm 2.79$ & $4.69 \pm 1.48$ & $3.85 \pm 1.43$ & $1.53 \pm 0.48$ & $48.49 \pm 8.60$ \\
\hline Mean \pm SD Range & $8.55-11.43$ & $6.98-8.65$ & $5.35-7.35$ & $4.25-5.75$ & $2.92-4.84$ & $1.11-1.78$ & $34.1-56.38$ \\
\hline p-values & \multicolumn{7}{|c|}{$\begin{array}{l}\text { ECC vs. DCC; E vs. ECC \& DCC; F vs. ECC, DCC \& E; A vs. B, C vs. D } \\
\qquad A l l(p<0.001)^{* *}\end{array}$} \\
\hline FMH Volume $(\mathrm{ml})$ Mean \pm SD & $14.15 \pm 15.97$ & $9.56 \pm 5.69$ & $5.30 \pm 3.29$ & $2.64 \pm 1.28$ & $1.56 \pm 0.89$ & ----- & ----- \\
\hline (Median) Range & $7(1.8-69)$ & $9.70(2-20.5)$ & $5.9(0.8-0.5)$ & $2.5(1.1-5.7)$ & $1.64(1.34-2.2)$ & ----- & ----- \\
\hline p-values & \multicolumn{7}{|c|}{$\begin{array}{l}\text { ECC vs. DCC; E vs. ECC \& DCC; F vs. ECC, DCC \& E; A vs. B, C vs. D } \\
\qquad \text { All }(p<0.001)^{* *}\end{array}$} \\
\hline
\end{tabular}

ECC (Early Cord Clamping group), DCC (Delayed Cord Clamping group), A (ECC caesarian section subgroup), B (ECC vaginal delivery subgroup), DCC (Caesarian section subgroup), D (DCC vaginaldelivery subgroup), E (Late pregnancy control subgroup), F (Non-pregnant control subgroup), G (Neonates control subgroup), FCM (Flow cytometer), FMH (Fetomaternal hemorrhage), No. (number), ${ }^{*}$ Significant, ${ }^{* * H i g h l y ~ S i g n i f i c a n t, ~ N S ~ N o n-s i g n i f i c a n t . ~}$ 
The difference in the FMH volume according to the cord clamping time protocol, demonstrated statistically significant increase in the ECC time group of females when compared to the DCC time one $(11.86 \pm 2.09$ and $3.97 \pm 2.82$, respectively; $\mathrm{p}<0.0001$ ).

Within the DCC time protocol, as regard the effect of delivery route on FMH volume, a statistically significant increase in FMH volume was found in the women group who had been perform vaginal delivery when compared to those women with caesarian section $(\mathrm{p}<0.01)$. On other hand, the caesarian section protocol of delivery showed statistically increase in the FMH volume in the women subjected to ECC time protocol in comparing to those with DCC protocol (B vs. D (9.56 \pm 5.69$) ;(2.64 \pm 1.28)$ respectively, $\mathrm{p}<0.05)$.

Also we noticed that within the vaginal delivery route, a significant increase in the FMH volume was found in the women group who were proceeded with ECC time protocol comparing to those with DCC (A vs. C (14.15 \pm 5.97); (5.30 \pm 3.29), respectively; $p<0.02$ ). There was a statistically significantly difference in the mean volume of FMH between the four mentioned subgroups $\mathrm{A}, \mathrm{B}, \mathrm{C}, \mathrm{D}$ (14.15 \pm 5.97, $9.56 \pm 5.69,5.30 \pm 3.29$ and $2.64 \pm 1.28$, respectively; $\mathrm{p}<0.0001)$. Most cases there were small FMH, while large incidence is about 3 in 100 cases.

Figures 1-4 showed the FCM analysis of fetal RBCs by FTIC in all the studied populations. Figure 1: non-pregnant female from total 20 women to know the normal percent of fetal RBCs in non-pregnant woman (No. of events $34 \%$ of gated RBCs 1.11), this is negative control for the studied populations. Figure 2 showed pregnant females in the $3^{\text {rd }}$ trimester from total 20 women as base line value for FMH that happen physiologically during pregnancy (No. of events $89 \%$ of gated RBCs 2.92). Figure 3 one neonates from 20 neonates as positive auto-control for fetal RBCs (No. of events $1041 \%$ of gated RBCs 34.11). Both positive and negative controls serve to adjust the set of work. The pregnant women

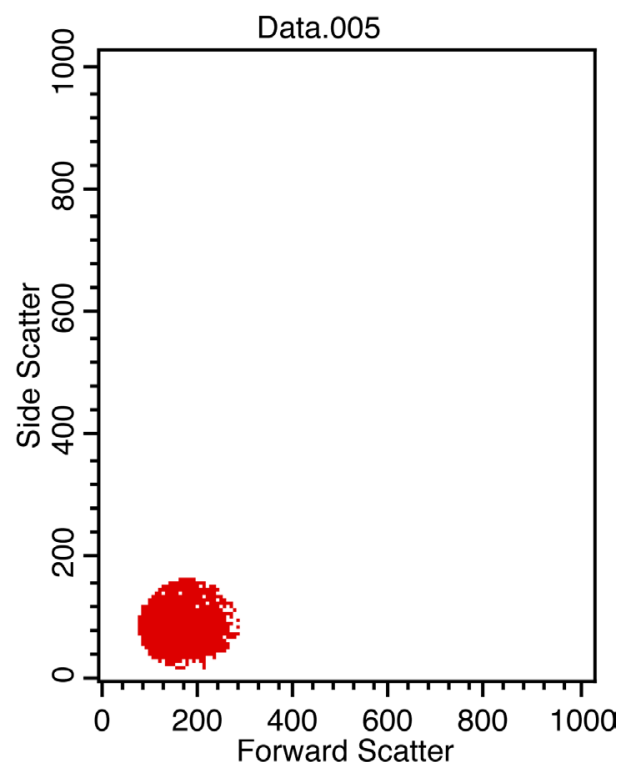

Figure 1. Non-pregnant female from total 20 women (No. of events $34 \%$ of gated RBCs 1.11). 


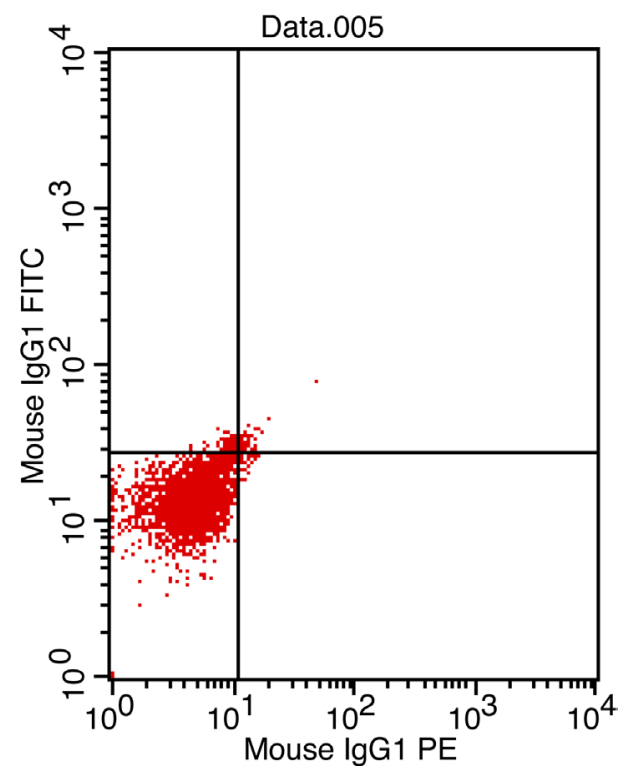

Figure 2. Pregnant female in the $3^{\text {rd }}$ trimester from total 20 women (No. of events $89 \%$ of gated RBCs 2.92).

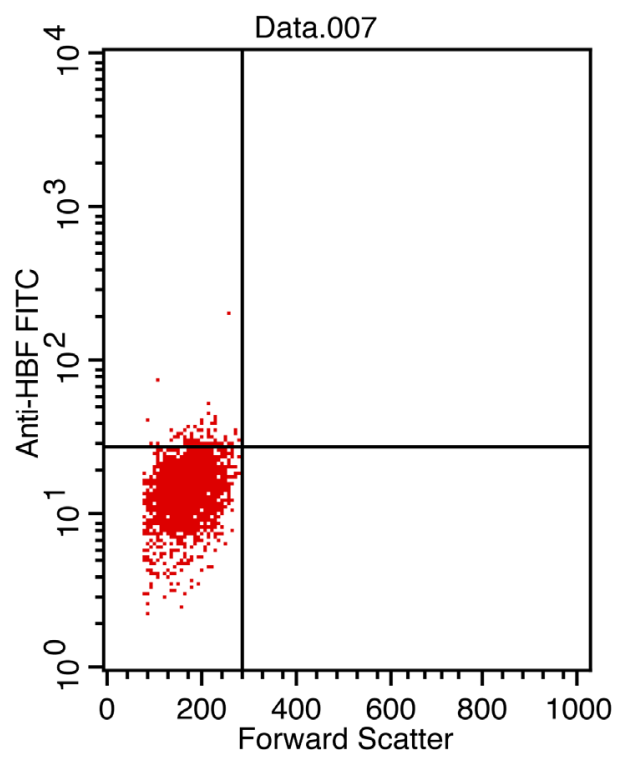

Figure 3. One neonate from 20 neonates as positive auto-control for fetal RBCs (No. of events $1041 \%$ of gated RBCs 34.11 ).

auto-control for FMH volume that is occurred normally regardless the type of delivery and time of cord clamping. Figure 4 showed one case with caesarian section from the delivered 100 women (No. of events $261 \%$ of gated RBCs 8.55 ).

\section{Discussion}

An accurate and reliable estimation of FMH is necessary, especially after certain conditions constitute inevitable risk of isoimmunization, such as abdominal trauma, invasive techniques like chorionic villous biopsy, amniocentesis [26]. In 
Quadrant Statistics

File: Data.007

Sample ID:

Tube: Untitled

Acquisition Date: 26-Nov-14

Gated Events: 3052

$X$ Parameter: Forward Scatter (Linear)

Quad Location: 288, 27
Log Data Units: Linear Values

Patient ID:

Panel: Untitled Acquisition Tube List

Gate: G1

Total Events: 10000

Y Parameter: Anti-HBF FITC (Log)

\begin{tabular}{crrrrrrr} 
Quad & Events & $\%$ Gated & $\%$ Total & X Mean & X Geo Mean & Y Mean & Y Geo Mean \\
\hline UL & 89 & 2.92 & 0.89 & 197.73 & 193.08 & 33.98 & 32.27 \\
UR & 0 & 0.00 & 0.00 & $* \star *$ & $* \star *$ & $* \star *$ & $* \star *$ \\
LL & 2963 & 97.08 & 29.63 & 168.23 & 163.41 & 14.52 & 13.73 \\
LR & 0 & 0.00 & 0.00 & $* \star *$ & $* \star *$ & $* \star *$ & $* \star *$
\end{tabular}

Figure 4. One case with caesarian section from the delivered 100 women (No. of events $261 \%$ of gated RBCs 8.55 ).

our study we use FCM method to determine FMH volume that occurred during labor and prefer it than other techniques as it has better precision, can prevent false-positive results in patients with increased F-cell counts due to other conditions [9] [10] [11]. Because maternal F cells have been reported to increase during the second trimester of pregnancy and misidentification of these $\mathrm{F}$ cells as fetal RBCs may occur especially in pregnant women with hereditary persistence of fetal hemoglobin, sickle cell disease, thalassemia, or a hematologic malignancy [27] [28] [29]. Formally (KBT) was based on the microscopic counting of fetal RBCs within the maternal blood on blood film, under acid conditions, it is inaccurate, leading to inappropriate dose of anti-Rh D immunoglobulin [13]-[30]. The value of FCM in detection of FMH is non-invasive technique used to adjust the dose of anti $\mathrm{D}$, also can detect fetal genetic diseases as it detects fetal cells, so PCR and DNA studies can be done [31]. FCM at first used surface antigen to detect FMH, nowadays FCM approaches use intra-cytoplasmic Ag detection of $\mathrm{Hb} F$ [32] [33] [34]. Recently monoclonal anti-Hb F antibody allows discrimination of three different populations: fetal RBCs, F cells, and adult RBCs [11]-[34]. As the time proceed, comparison of different reagents on FCM was done by Fong et al., (2013), who had used 2 kits, Trillium FMH Quick Quant a new kit including anti-Hb $\mathrm{F}$ antibody and propidium iodide (PI) which is a specific marker for nucleated cells to discriminate fetal cells from fetal RBCs [35]. The guidelines were done to improve inter-laboratory variations with FMH techniques based on gating strategies, Wong et al., (2013) had studied the automated analysis of fetal RBCs, was found strongly correlates with expert traditional manual analysis [36]. Also Gielezynska (2014) found that an increase population of $\mathrm{Hb} \mathrm{F}$ positive cells can be detect in a healthy women [37]. For this reason we used non-pregnant women as negative control for FMH whom contained normal percent of $\mathrm{Hb} \mathrm{F}$ and women in the third trimester to determine reference ranges of fetal RBCs in maternal blood during the last trimester of an uncomplicated pregnancy as reported by de Wite et al., (2011) [26]. In this study we use both positive and negative control that serve to adjust the set of work. Women in 
late pregnancy are considered physiologic control for FMH volume that is occurred normally regardless the type of delivery and time of cord clamping so give idea about base line data of FMH.

Our results denote that the obstetric protocol of delivery affect much more FMH volume, so we find that DCC time protocol delivery decreases the volume of FMH, this effect can be strengthen by deciding caesarian section route of delivery. Our data is partially in accordance with Heike et al. (2012), who studied the effect of DCC time on FMH volume, who said that, cord clamping protocol was the only parameter can induce a significant difference in FMH [38]. These findings clearly agree with the results of Parul et al. (2015) and Faucher et al. (2016) [39] [40]. The result of this study also agree with the results of Colleen et al. (2016), who found that the incidence of $\mathrm{FMH}$, was significantly lower in females who subjected to DCC protocol [41]. From other mentioned studies one can conclude that beneficial effects of DCC on maternal and neonatal outcomes, a significant increase in endogenous stem cells in umbilical cord samples following DCC, so more neonatal benefits can achieved [42] [43]. Finally we can advise the obstetricians to decide caesarian section delivery combined with DCC protocol especially in vulnerable females to develop isoimmunization like $\mathrm{Rh}$ negative or women who exposed to invasive procedures. It is important to perform FCM assay of fetal RBCs as a routine investigation in perinatal care program especially to the critical category of women to provide a decision for delivery route and how the postpartum period care achieved.

\section{Conclusion}

FCM is considered the best applicable, rapid and economic method for detection the degree of FMH severity and can be used as perinatal routine test providing suitable obstetric techniques to decrease the possibility of isoimmunization. DCC time and caesarian section protocols decrease much more FMH.

\section{Recommendation}

Late pregnancy and postpartum fetal RBCs estimation by FCM especially in Rh negative women and those exposed to trauma or invasive techniques should be done as a routine investigation to decrease FMH and minimize isoimmunization.

\section{Conflict of Interest}

All authors declare that they have no conflict of interest.

\section{Ethical Approval}

All procedures performed in studies involving human participants were in accordance with the ethical standards of the institutional and/or national research committee and with the 1964 Helsinki declaration and its later amendments or comparable ethical standards, written informed consent was obtained from all women participate in the research, they informed that the blood samples for re- 
search purpose.

\section{References}

[1] Rubod, C., Deruelle, P., Le Goueff, F., Tunez, V., Fournier, M. and Subtil, D. (2007) Long-Term Prognosis for Infants after Massive Fetomaternal Hemorrhage. Obstetrics \& Gynecology, 110, 256-260. https://doi.org/10.1097/01.AOG.0000271212.66040.70

[2] Dziegiel, M.H., Nielsen, L.K. and Berkowicz, A. (2006) Detecting Fetomaternal Hemorrhage by Flow-Cytometry. Current Opinion in Hematology, 13, 490-495. https://doi.org/10.1097/01.moh.0000245687.09215.c4

[3] Martin, W.L., Durrant, L.G. and Liu, D.T. (1998) Non-Invasive Fetal Cell Isolation from Maternal Blood. British Journal of Obstetrics and Gynaecology, 105, 576-583. https://doi.org/10.1111/j.1471-0528.1998.tb10170.x

[4] Bowman, J.M., Pollock, J.M. and Penston, L.E. (1986) Fetomaternal Trans-Placental Hemorrhage during Pregnancy and after Delivery. Vox Sanguinis, 51, 117-121. https://doi.org/10.1111/j.1423-0410.1986.tb00226.x

[5] Said, S. and Mc Parland, P. (2006) Update on the Management of Non-Anti D Antibodies. Irish Medical Journal, 99, 55-56.

[6] Catarino, C., Rebelo, I., Belo, L., Rocha-Pereira, P., Rocha, S., Byer Castro, E., Patricio, B., Quintanilha, A. and Santos-Silva, A. (2009) Erythrocyte Changes in Pre-Eclampsia: Relationship between Maternal and Cord Blood Erythrocyte Damage. Journal of Perinatal Medicine, 37, 19-27. https://doi.org/10.1515/JPM.2009.007

[7] Nance, S.J., Nelson, J.M. and Arndt, P.A. (1989) Quantitation of Fetal-Maternal Hemorrhage by Flowcytometry: A Simple and Accurate Method. American Journal of Clinical Pathology, 91, 288-292. https://doi.org/10.1093/ajcp/91.3.288

[8] Lubenko, A., Collier, R. and Williams, M. (1997) Quantitating Fetomaternal Hemorrhages of D+ Red Cells Using an FITC- Conjugated IgG Monoclonal Anti-D by Flowcytometry: A Case Report. Immunohematology, 13, 12-14.

[9] Mundee, Y., Bigelow, N.C. and Davis, B.H. (2000) Simplified Flow Cytometric Method for Fetal Hemoglobin Containing Red Blood Cells. Cytometry, 42, 389-393. https://doi.org/10.1002/1097-0320(20001215)42:6<389::AID-CYTO1007>3.0.CO;2-I

[10] Lambertino, J.R. and Villegas, S.M. (2014) Rh Alloimmunization in Pregnant Women, Look to Diagnosis and Therapeutic Approach. Ginecología y Obstetricia de México, 82, 744-754.

[11] Uriel, M., Subira, D., Plaza, J., Castanon, S., Canamares, M. and Recasens, J.D. (2010) Identification of Fetomaternal Hemorrhage around Labor Using Flow Cytometry Immunophenotyping. European Journal of Obstetrics \& Gynecology and Reproductive Biology, 151, 20-25. https://doi.org/10.1016/j.ejogrb.2010.03.008

[12] Günel, T., Kalelioğlu, İ., Ermiş, H. and Aydınl, K. (2010) Detection of fetal Rh D Gene from Maternal Blood Maternal Kandan Fetal RhD Tayini. Journal of the Turkish-German Gynecological Association, 11, 82-85. https://doi.org/10.5152/jtgga.2010.04

[13] Kleihauer, E., Braun, H. and Betke, K. (1957) Demonstration of Fetal Hemoglobin in Erythrocytes of a Blood Smear. Wiener klinische Wochenschrift, 35, 637-638. (In German) https://doi.org/10.1007/BF01481043

[14] Nance, S.J., Nelson, J.M. and Arndt, P.A. (1989) Quantitation of Fetal-Maternal Hemorrhage by Flow Cytometry: A Simple and Accurate Method. American Journal of Clinical Pathology, 91, 288-292. https://doi.org/10.1093/ajcp/91.3.288

[15] Grant, R. and Keidan, J. (2009) False Positive Kleihauer Results: An Unusual Cause 
in a Postnatal Patient in Remission from Acute Myeloid Leukemia. International Journal of Laboratory Hematology, 31, 241-244. https://doi.org/10.1111/j.1751-553X.2007.00974.X

[16] Farias, M., Dal Bo, S., de Castro, S., da Silva, A., Bonazzoni, J., Scotti, L., Almeida, S.H. and Costa, M. (2016) Flowcytometry in Detection of Fetal Red Blood Cells and Maternal F Cells to Identify Fetomaternal Hemorrhage. Fetal and Pediatric Pathology, 5, 1-7.

[17] Merron, B.M., Maguire, K. and Morris, K. (2015) When Is an Anti-D Antibody Not an Anti-D Antibody? Transfusion Medicine, 25, 115-117. https://doi.org/10.1111/tme.12200

[18] McDonald, S.J., Middleton, P., Dowswell, T. and Morris, P.S. (2013) Effect of Time of Umbilical Cord Clamping of Term Infants on Maternal and Neonatal Outcomes. Cochrane Database of Systemic Reviews, 2013, CD004074.

[19] Lainez, V.B, Berger, A.E, Cafferta, T.M.L. and Belizan, C.J.M. (2005) Early or Late Umbilical Cord Clamping? A Systematic Review of the Literature. Anales de Pediatría, 63, 14-21. (In Spanish)

[20] Boistridge, J., Bell, T., Dean, B., Mackley, A., Moore, G., Swift, C., Viscount, D., Paul, D.A. and Pearlman, S. (2016) A Quality Improvement Initiative for Delayed Umbilical Cord Clamping in Very Low Birth Weight Infants. BMC Pediatrics, 16, 155. https://doi.org/10.1186/s12887-016-0692-9

[21] Allan, D.S., Scrivens, N., Lawless, T., Oppenheimer, K., Walker, M., Petraszko, T. and Eloazzen, H. (2016) Delayed Clamping of the Umbilical Cord after Delivery and Implications for Public Cord Blood Banking. Transfusion, 56, 662-665. https://doi.org/10.1111/trf.13424

[22] Hooper, S.B., Binder-Heschl, C., Polglase, G.R., Gill, A., Kluckow, M., Wallace, E.M., Blank, D. and te Pas, A. (2016) The Timing of Umbilical Cord Clamping at Birth, Physiological Consideration. Maternal Health, Neonatology and Perinatology, 2, 4. https://doi.org/10.1186/s40748-016-0032-y

[23] Ceriani Cernadas, J.M., Carroli, G. and Pellegrini, L. (2006) The Effect of Timing of Cord Clamping on Neonatal Venous Hematocrit Values and Clinical Outcome at Term: A Randomized, Controlled Trial. Pediatrics, 117, e779-e786. https://doi.org/10.1542/peds.2005-1156

[24] Britto, P., Lye, S., Proulx, K., Yousafzal, A.K., Matthews, S., Viavada, T., Perez, R., Rao, N., Ip, P., Fernald, L.C., MacMillan, H., Hanson, M., Wachs, T.D., Yao, H., Yoshikawa, H., Cerezo, A., Leckman, J.F. and Bhutta, Z. (2017) Nurturing Care Promoting Early Childhood Development. The Lancet, 389, 91-102. https://doi.org/10.1016/S0140-6736(16)31390-3

[25] Gujral, S., Tembhare, P., Badrinath, Y., Subramanian, P.G., Kumar, A. and Sehgal, K. (2009) Intracytoplasmic Antigen Study by Flowcytometry in Hematolymphoid Neoplasm. Indian Journal of Pathology and Microbiology, 52, 135-144. https://doi.org/10.4103/0377-4929.48902

[26] De Wit, H., Nabbe, K., Kooren, J., Adriaansen, H., Roelandse-Koop, E., Schuitemaker, J. and Hoffmann, J. (2011) Reference Values of Fetal Erythrocytes in Maternal Blood during Pregnancy Established Using Flowcytometry. American Journal of Clinical Pathology, 136, 631-636. https://doi.org/10.1309/AJCPHL3VXY0VMLXL

[27] Pastoret, C., Le Priol, J., Fest, T. and Roussel, M. (2013) Evaluation of FMH QuikQuant for the Detection and Quantification of Fetomaternal Hemorrhage. Cytometry, 84, 37-43. https://doi.org/10.1002/cyto.b.21052

[28] Pembrey, M.E., Weatherall, D.J. and Clegg, J.B. (1973) Maternal Synthesis of Hemoglobin F in Pregnancy. Lancet, 1, 1350-1354. 
https://doi.org/10.1016/S0140-6736(73)91675-9

[29] Janssen, W.C. and Hoffmann, J.J. (2002) Evaluation of Flow Cytometric Enumeration of Fetal Erythrocytes in Maternal Blood. Clinical Laboratory Hematology, 24, 89-92. https://doi.org/10.1046/j.1365-2257.2002.00438.x

[30] Pelikan, D.M., Scherjon, S.A., Mesker, W.E., et al. (2004) Quantification of Fetomaternal Hemorrhage: A Comparative Study of the Manual and Automated Microscopic Kleihauer-Betke Tests and Flowcytometry in Clinical Samples. American Journal of Obstetrics \& Gynecology, 191, 551-557. https://doi.org/10.1016/j.ajog.2004.01.007

[31] Subirá, D., Uriel, M. and Serrano, C. (2011) Significance of the Volume of Fetomaternal Hemorrhage after Performing Prenatal Invasive Tests. Cytometry Part B: Clinical Cytometry, 80, 38-42. https://doi.org/10.1002/cyto.b.20548

[32] Duckett, J.R. and Constantine, G. (1997) The Kleihauer Technique: An Accurate Method of Quantifying Fetomaternal Haemorrhage? British Journal of Obstetrics and Gynaecology, 104, 845-846. https://doi.org/10.1111/j.1471-0528.1997.tb12032.x

[33] Shen, R. and Gerald Sandler, S. (2015) Transfusion Medicine Illustrated, Miscounting Even One Lymphocyte in the Kleihauer-Betke Assay Can Results in Overdose Immunoglobulin. Transfusion, 55, 2069. https://doi.org/10.1111/trf.13056

[34] Davis, B.H., Olsen, S., Bigelow, N.C. and Chen, J.C. (1998) Detection of Fetal Red Cells in Fetomaternal Hemorrhage Using a Fetal Hemoglobin Monoclonal Antibody by flow Cytometer. Transfusion, 38, 749-775.

https://doi.org/10.1046/j.1537-2995.1998.38898375514.x

[35] Fong, E.A., Finlayson, J., Robins, F., Davies, J., Joseph, J., Rossi, E. and Grey, D.E. (2013) Evaluation of a New Rapid Anti-Hb F FITC Assay, Trillium Quik Quant, for Detection and Quantitation of Fetomaternal Haemorrhage. International Journal of Laboratory Hematology, 35, 106-110. https://doi.org/10.1111/j.1751-553X.2012.01463.x

[36] Wong, L., Hunsberger, B.C., Bruce Bagwell, C. and Davis, B.H. (2013) Automated Quantitation of Fetomaternal Hemorrhage by Flow Cytometer for Hb F-Containing Fetal Red Blood Cells Using Probability State Modeling. International Journal of Laboratory Hematology, 35, 548-554. https://doi.org/10.1111/ijlh.12060

[37] Gielezynska, A., Stachurska, A., Fabijańska-Mitek, J., Debska, M., Burzyńska, B., Rawa, K. and Pawlik, K. (2014) Fetomaternal Hemorrhage Assessment in a Woman with a Large Population of Red Blood Cells Containing Fetal Hemoglobin. Ginekologia Polska, 85, 614-618.

[38] Rabe, H., Diaz-Rossello, J., Duley, L. and Dowswell, T. (2012) Effect of Timing of Umbilical Cord Clambing and Other Strategies to Influence Placental Transfusion at Preterm Birth on Maternal and Infant Outcome. Cochrane Pregnancy and Childbirth Group, 2012, CD003248.

[39] Christian, P., Mullany, L.C., Hurley, K.M., Katz, J. and Black, R. (2015) Nutrition and Maternal, Neonatal and Child Health. Siminar in Perinatology, 39, 361-372. https://doi.org/10.1053/j.semperi.2015.06.009

[40] Faucher, M.A., Riley, C., Prater, L. and Reddy, M.P. (2016) Midwives in India: Delayed Cord Clamping Intervention Using Simulation. International Nursing Review, 63, 437-444. https://doi.org/10.1111/inr.12264

[41] Fulton, C., Stoll, K. and Thordarson, D. (2016) Bedside Resuscitation of Newborns with an Intact Umbilical Cord: Experiences of Midwives from British Columbia. Midwifery, 34, 42-46. https://doi.org/10.1016/j.midw.2016.01.006

[42] Lassi, Z.S., Middleton, P., Crowther, C. and Bhutta, Z.A. (2015) Interventions to 
Improve Neonatal Health and Later Survival: An Overview Systamtic Reviews. EBioMedicine, 2, 985-1000. https://doi.org/10.1016/j.ebiom.2015.05.023

[43] Lawton, C., Acosta, S., Watson, N., Gonzales-Portillo, C., Diamandis, T., Tajiri, N., Kaneko, Y., Sanberg, P.R. and Borlongan, C.V. (2015) Enhancing Endogenus Stem Cells in the Neoborne via Delayed Umbilical Cord Clamping, Neural Regeneration Research, 10, 1359-1362. https://doi.org/10.4103/1673-5374.165218

Submit or recommend next manuscript to SCIRP and we will provide best service for you:

Accepting pre-submission inquiries through Email, Facebook, LinkedIn, Twitter, etc. A wide selection of journals (inclusive of 9 subjects, more than 200 journals) Providing 24-hour high-quality service User-friendly online submission system Fair and swift peer-review system Efficient typesetting and proofreading procedure Display of the result of downloads and visits, as well as the number of cited articles Maximum dissemination of your research work

Submit your manuscript at: http://papersubmission.scirp.org/ Or contact ojbd@scirp.org 